\title{
Conditions for the Extraction of Polyphenols from Radiata Pine (Pinus radiata) Bark for Bio-Foam Preparation ${ }^{1}$
}

\author{
Min $\mathrm{LEE}^{2} \cdot \mathrm{Su}$ Hyeon $\mathrm{JEONG}^{3} \cdot$ Sung Phil MUND ${ }^{4, \dagger}$
}

\begin{abstract}
The use of polyphenol extracts from radiata pine (Pinus radiata) bark as raw materials for bio-foams was investigated along with the optimal $\mathrm{NaOH}$ extraction conditions. The targeted yield of alkaline extracts was $60 \%$, and the targeted $\mathrm{pH}$ was 11 to 12 . The radiata pine bark was composed of $70 \%$ of a $1 \% \mathrm{NaOH}$ extract, which contained mainly polyphenols, such as proanthocyanidin (PA). As the particle size of the bark decreased, the yield of the $1 \% \mathrm{NaOH}$ extracts increased from 57 to $87 \%$. A range of $\mathrm{NaOH}$ concentrations, liquor ratios, and extraction times were explored to establish an economic polyphenol extraction method. More than $60 \%$ of the alkaline extract was extracted, and the pH of the extract was approximately 12 when the optimum extraction conditions were employed, i.e., a liquor to bark ratio of 5:1, a $\mathrm{NaOH}$ dosage of 17 to $18 \%$ based on the bark weight, and a $1 \mathrm{~h}$ extraction time. Following neutralization of the alkaline extract, structural analysis indicated severe structural changes in the PA during the alkaline extraction. Because the alkaline extract was barely soluble in the solvent used for the structural analyses, it is assumed that chemical modification is required to increase the solubility of the alkaline extract for the production of bio-foams.
\end{abstract}

Keywords: polyphenol, bio-foams, radiata pine bark, alkali

\section{INTRODUCTION}

The South Korean government has proposed a $31 \%$ reduction in greenhouse gas $(\mathrm{GHG})$ emissions by the end of 2020. One of the strategies for achieving this ambitious goal is the construction of green buildings by strengthening energy standards for new buildings, and promoting energy efficiency improvements for the existing ones. The development and manufacture of super-insulation materials is vital to achieve this goal. Currently, petroleum- and chemical-based insulation materials, such as styrofoam and urethane foam, are the most widely employed in the domestic insulation market in South Korea. These materials suffer from a number of disadvantages, including poor biodegradation and the associated pollution issues upon disposal. However, the use of wood resources is necessary to promote the recycling of forest resources and the long-term storage of carbon under the GHG-reduction policy and new climate system (i.e., post-2020) reduction target under the Framework Act on Low Carbon, Green Growth. In addition, the law surround-

\footnotetext{
${ }^{1}$ Date Received September 8, 2020, Date Accepted October 28, 2020

2 Department of Forest Products, National Institute of Forest Science, Seoul 02455, Republic of Korea

${ }^{3}$ Institute of Agricultural Science and Technology, Jeonbuk National University, Jeonju 54896, Republic of Korea

${ }^{4}$ Department of Wood Science and Technology, Jeonbuk National University, Jeonju 54896, Republic of Korea

$\dagger$ Corresponding author: Sung Phil MUN (e-mail: msp@jbnu.ac.kr, ORCID: 0000-0002-3475-4965)
} 
ing the sustainable use of wood (Korean Law no. $167112020)$ must reconsider the value of timber resources and expand the utilization of unused domestic wood resources to support the policy of promoting domestic timber for revitalizing the timber industry. In this context, the development of safe and reliable methods for the mass production of eco-friendly raw materials by utilizing domestic wood resources and manufacturing bio-composite materials is essential.

In 2019, South Korea's total timber imports were approximately 2.6 million $\mathrm{m}^{3}$, and more than $75 \%$ of them constituted radiata pine (Pinus radiata; KFS, 2020). In the wood-related industry, tree bark, which makes up 9 to $15 \%$ of the total wood employed, is treated as waste, and is typically collected in the wood peeling process for use as a fuel resource or for mulching. To date, various studies have utilized pine bark and wood resources for cosmetics and medical purposes (Mun, 2008; Mun et al., 2010; Kim et al., 2018; Nam et al., 2018; Masendra et al., 2019). In South Korea, the applicability of mulching agents (Park et al., 2014), heavymetal adsorbents (Song et al., 2009; Mun et al., 2010), and dye stuffs (Mun et al., 2010) has been examined. Polyphenols comprise 50 to $60 \%$ of these pine barks, and proanthocyanidin (PA), which can be extracted using hot water, is the most important constituent ( $\mathrm{Ku}$ et al., 2007). PA is a catechin-based polymer comprising a large number of hydroxyl groups. The structural properties of these polyphenols originating from pine bark render them suitable substitutes for the polyols used in the production of bio-foams. Indeed, a variety of approaches have been employed to add value to wood and bark extracts, for example, to use them in foam manufacturing (Tondi et al., 2008; Zhou et al., 2013; Basso et al., 2014).

The transition from bark and waste wood to petroleum-based insulation materials would contribute greatly to the economy and the environment in countries such as Korea, where the majority of wood is imported. The development of cost-efficient methods for the extraction of polyphenols from pine bark is essential. The purpose of this study is to establish a cost-efficient and effective method for the extraction of polyphenols from pine bark, in addition to determining their utility as raw materials in bio-foam manufacturing through structural analysis.

\section{EXPERIMENTAL}

\subsection{Materials}

The radiata pine bark was collected from a lumberyard in Unid Co., Ltd. (Gunsan-si, Korea), and the dirt, scales, and inner barks were removed from the raw bark. The bark was then ground to a particle size of $\leq 1$ $\mathrm{cm}$ and processed using a high-speed grinder to give a powder with a particle size of $\leq 1 \mathrm{~mm}$. The prepared bark powder was stored at $4{ }^{\circ} \mathrm{C}$. A $\mathrm{NaOH}$ solution (93\%) was used for alkali extraction of the polyphenols from the bark. All chemicals employed herein were of American Chemical Society (ACS) grade and were purchased from DaeJung Chemical \& Metals (Sihungsi, Korea) and Sigma-Aldrich (St. Louis, MO, USA).

\subsection{Chemical composition of radiata pine bark}

The prepared bark powder (150 g) was sieved to give samples of 5 different mesh sizes, i.e., 40,40 to 80,80 to 100,100 to 200 , and 200 mesh. The hot water and $1 \% \mathrm{NaOH}$ extracts were prepared using TAPPI test methods (T-207 cm-99 2008; T-212 om-02 2002), and ash and total lignin contents were determined (TAPPI T-211 2002; T-222 om-11 2011). However, the lignin content of the pine bark obtained using the Klason method was overestimated due to the presence of polyphenols. Therefore, the bark polyphenols were initially removed (obtained) by extraction with $1 \% \mathrm{NaOH}$, and thereafter the polyphenol-corrected lignin value was determined using the residues obtained 
Conditions for the Extraction of Polyphenols from Radiata Pine (Pinus radiata) Bark for Bio-Foam Preparation

following $1 \% \mathrm{NaOH}$ extraction.

\subsubsection{Optimum $\mathrm{NaOH}$ extraction conditions}

A $\mathrm{NaOH}$ solution was used for extraction of the bark polyphenols. The alkaline extraction conditions were optimized by studying various extraction parameters, such as the bark-to- $\mathrm{NaOH}$ ratio, the liquor ratio, and the extraction time. All experiments were carried out using 1 $\mathrm{g}$ (o.d.) samples of radiata pine bark. Initially, the samples were extracted using $1 \% \mathrm{NaOH}$ solutions in ratios $(\mathrm{w} / \mathrm{w})$ of $6.25,12.5,25$, and 50 to the bark weight, and the yields of the $1 \% \mathrm{NaOH}$ extracts were determined along with their $\mathrm{pH}$ values. Subsequently, the amount of $\mathrm{NaOH}$ used for the extraction was fixed, and the yields of the $\mathrm{NaOH}$ extract were studied as a function of the liquor ratio. In addition, using a fixed concentration of the $\mathrm{NaOH}$, the $\mathrm{NaOH}$ extract yields were measured at different extraction times (5 to $120 \mathrm{~min}$ ). Finally, the extraction yield and $\mathrm{pH}$ were measured upon variation in the $\mathrm{NaOH}$ dose $(12.5,17$, or $18 \%)$ at a fixed extraction time $(1 \mathrm{~h})$ and fixed liquor ratio (5).

\subsubsection{IR spectroscopy}

One milligram of each freeze- and vacuum-dried extract (either hot water or $\mathrm{NaOH}$ extract) was mixed with $\mathrm{KBr}(100 \mathrm{mg})$ and ground in an agate mortar to prepare a powder that was used to prepare a thin disc. The prepared sample disk was mounted on the device and was scanned 10 times in a range of 400 to $4000 \mathrm{~cm}^{-1}$ using an FTIR spectrophotometer (8201 PC, Shimadzu, Kyoto, Japan) to obtain the transmission spectrum.

\subsection{3. ${ }^{13} \mathrm{C}$ NMR analysis}

The samples obtained after neutralization of the
$\mathrm{NaOH}$ extracts contained large amounts of salt, and were barely soluble in the acetone- $d_{6} / \mathrm{D}_{2} \mathrm{O}$ solvent system used for ${ }^{13} \mathrm{C}$ NMR analysis. Therefore, desalting was performed using a cation-exchange resin (Amberlite IR $120 \mathrm{H}$, Alfa Aesar, Haverhill, MA, USA) to ensure complete dissolution of the sample. The desalted solutions were lyophilized, and a sample $(100 \mathrm{mg})$ of the resulting powder was dissolved using a $\sim 1: 1$ ratio $(\mathrm{v} / \mathrm{v})$ of acetone- $d_{6}$ to $\mathrm{D}_{2} \mathrm{O}$ in a $10 \mathrm{~mL}$ conical flask. The sample solutions were transferred to $1.7 \mathrm{~mL}$ microtubes and subjected to centrifugation at $15,000 \mathrm{rpm}$ for $10 \mathrm{~min}$ at $20{ }^{\circ} \mathrm{C}$. The resulting solutions were passed through a pipette containing glass wool and transferred an NMR tube. For comparison, the hot water extracts were taken up in a $\sim 1: 1$ mixture $(\mathrm{v} / \mathrm{v})$ of acetone- $d_{6}$ and $\mathrm{D}_{2} \mathrm{O}$, filtered, and transferred to an NMR tube. The samples were analyzed using a 400 MHz NMR spectrometer (AL-400, JEOL, Tokyo, Japan) in the center for university-wide research facilities at Jeonbuk National University.

\section{RESULTS AND DISCUSSION}

\subsection{Chemical composition of radiata pine bark}

Table 1 shows the chemical composition of the radiata pine bark sample in terms of ash, hot water extract, $1 \% \mathrm{NaOH}$ extract, and Klason lignin contents (before and after $1 \% \mathrm{NaOH}$ extraction). The contents of ash, hot water extract, and Klason lignin after $1 \% \mathrm{NaOH}$ extraction (polyphenol-corrected lignin content) were $0.70,28.42 \%$, and $14.44 \%$, respectively. The $1 \% \mathrm{NaOH}$ extract yield was $69.60 \%$, and the polyphenols content was $51.88 \%$. The polyphenols were calculated by sub-

Table 1. Composition of the Radiata Pine Bark

\begin{tabular}{cccccc}
\hline \multirow{2}{*}{ Ash (\%) } & \multirow{2}{*}{$\begin{array}{c}\text { Hot water } \\
\text { extract }(\%)\end{array}$} & $\begin{array}{c}1 \% \mathrm{NaOH} \\
\text { extract }(\%)\end{array}$ & $\begin{array}{c}\text { Polyphenols } \\
(\%)\end{array}$ & \multicolumn{2}{c}{ Klason Lignin $(\%)$} \\
\cline { 5 - 6 } & 28.42 & 69.60 & 51.88 & 66.32 & Before $1 \%$ NaOH extraction After $1 \%$ NaOH extraction \\
\hline \hline 0.70 & 28.42 & & 5.44 \\
\hline
\end{tabular}


tracting the Klason lignin after $1 \% \mathrm{NaOH}$ extraction from the Klason lignin before $1 \% \mathrm{NaOH}$ extraction. Polyphenols represented $75 \%$ of the $1 \% \mathrm{NaOH}$ extract. Because the majority of polyphenols present in radiata pine bark were extracted by alkali ( $\mathrm{Ku}$ et al. 2007), the content of $1 \% \mathrm{NaOH}$ extracts can be used as a measure of the total polyphenol content.

The sample powders were separated according to their particle sizes using 40-, 80-, 100-, and 200-mesh sieves. As shown in Table 2, the 80 to 100 mesh particles (150 to $180 \mu \mathrm{m}, 40.4 \%$ ) were the most dominant in the raw radiata pine bark powder. The $1 \% \mathrm{NaOH}$ extract and total lignin (Klason lignin plus acid-soluble lignin) contents of the bark powder were also determined, and the results are presented in Table 2. As the particle size of the radiata pine bark powder decreased, the amount of $1 \% \mathrm{NaOH}$ extract increased, while the Klason lignin and acid-soluble lignin contents decreased.

The optimum particle size required for efficient bark extraction was determined from the extraction yield. Higher particle sizes, i.e., powders that passed through the 80 mesh sieve, showed polyphenol contents of $\geq$ $70 \%$ based on the $1 \% \mathrm{NaOH}$ extract content (Table 2). The raw bark powder (i.e., non-sieved bark powder) consisted of $\geq 60 \%$ of these particles, with only $6.4 \%$ of the powder failing to pass through the 40 mesh. In addition, the powder that passed through the 200-mesh comprised of $86.62 \%$ of $1 \% \mathrm{NaOH}$ extract, which in- dicated that this powder size was superior in terms of bark polyphenol extraction. However, the total content amounted to only $10 \%$ of the total bark. Overall, these results suggest that the powder obtained by the passing through the $1 \mathrm{~mm}$ sieve is suitable for the extraction of polyphenols from radiata pine bark.

\section{2. $1 \% \mathrm{NaOH}$ extraction conditions}

The extraction of polyphenols from radiata pine bark is facile using an alkali solution (Ku et al., 2007). Thus, the optimal and most economic alkali extraction conditions to obtain extraction yields of $\geq 60 \%$ were determined. Fig. 1 show the extraction yields obtained using different ratios $(\mathrm{w} / \mathrm{w})$ of the $1 \% \mathrm{NaOH}$ solution (i.e., $6.25,12.5,25$, and 50 ) to extract $1 \mathrm{~g}$ of the bark powder.

The extract yields increased upon increasing the ratio of the $1 \% \mathrm{NaOH}$ solution, which was attributed

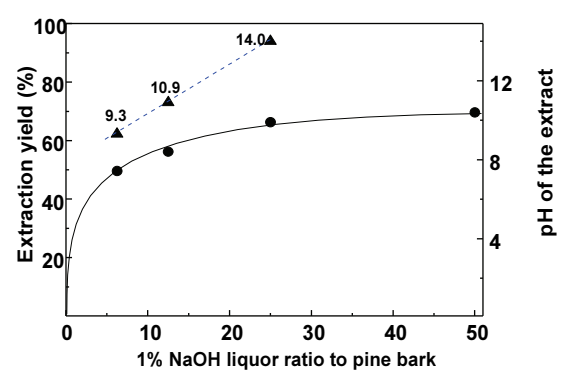

Fig. 1. Changes in extraction yield and $\mathrm{pH}$ according to $1 \% \mathrm{NaOH}$ solution ratio to pine bark.

Table 2. Particle Proportions and Contents of the $1 \% \mathrm{NaOH}$ Extract, Klason Lignin, and Acid-soluble Lignin of the Bark Powders of Various Particle Sizes

\begin{tabular}{|c|c|c|c|c|c|}
\hline \multirow{2}{*}{ Powder size $(\mu \mathrm{m})$} & \multirow{2}{*}{$\begin{array}{l}\text { Proportion } \\
\qquad \%)\end{array}$} & \multirow{2}{*}{$\begin{array}{c}1 \% \mathrm{NaOH} \text { extract } \\
(\%)\end{array}$} & \multicolumn{3}{|c|}{ Lignin (\%) } \\
\hline & & & Klason & Acid-soluble & Total \\
\hline Non-sieved bark (1 mm pass) & 100 & 69.60 & 14.44 & 0.22 & 14.66 \\
\hline 40 mesh $(\geq 425)$ & 6.4 & 57.24 & 21.66 & 0.37 & 22.03 \\
\hline $40-80$ mesh $(180-425)$ & 32.1 & 64.26 & 16.64 & 0.23 & 16.87 \\
\hline $80-100$ mesh $(150-180)$ & 40.4 & 70.32 & 14.28 & 0.16 & 14.44 \\
\hline $100-200$ mesh (75-150) & 12.2 & 76.67 & 11.26 & 0.12 & 11.38 \\
\hline 200 mesh pass $(\leq 75)$ & 8.9 & 86.62 & 6.44 & 0.08 & 6.52 \\
\hline
\end{tabular}


Conditions for the Extraction of Polyphenols from Radiata Pine (Pinus radiata) Bark for Bio-Foam Preparation

to an increase in the amount of $\mathrm{NaOH}$ present in solution. Using a ratio of 12.5 , an extraction yield of $56 \%$ was achieved, along with an extract $\mathrm{pH}$ value of 10.9 , while a ratio of 25 gave a yield of $\sim 66 \%$ and a $\mathrm{pH}$ of 14. It was apparent that the extraction yield and $\mathrm{pH}$ were dependent on the total amount of $\mathrm{NaOH}$ added. The ratio of 12.5 was considered optimal, despite the target goal not being reached. Next, the effect of the extraction yield upon variation in the liquor ratio with fixed amount of $\mathrm{NaOH}$ (i.e., $0.125 \mathrm{~g}$ ) was investigated.

As outlined in Table 3, when the $\mathrm{NaOH}$ amount was fixed and liquor ratio was the only variable, the extraction yield was determined. Even upon increasing the extraction liquor ratio, the extraction yield remained almost constant at 56 to $57 \%$, indicating that the efficiency of the bark extraction was completely dependent on the weight of $\mathrm{NaOH}$ employed. This indicates that polyphenol extraction from the pine bark was greatly dependent on the amount of $\mathrm{NaOH}$ present in solution.

Because the extraction yield was greatly dependent on the alkali concentration, in consideration of the economic efficiency, the extraction liquor ratio was examined using a lower liquor ratio of 5 to determine its influence on the extraction time. The liquor ratio and the amount of $\mathrm{NaOH}$ were fixed at 5 and $12.5 \%$ relative to the bark weight, respectively, and the variation in extraction yield with the extraction time was examined.

As shown in Fig. 2, approximately $52 \%$ of the extract (i.e., containing the polyphenols) was extracted

Table 3. Extraction Yields According to the Liquor Ratio When Using the Same Amount of $\mathrm{NaOH}$

\begin{tabular}{ccc}
\hline Liquor Ratio $(\mathrm{w} / \mathrm{w})$ & $\mathrm{NaOH}(\mathrm{g})$ & Extraction Yield (\%) \\
\hline \hline 5 & & 56.99 \\
6.25 & 0.125 & 57.37 \\
8 & & 56.93 \\
12.5 & & 56.20 \\
\hline
\end{tabular}

Extraction time: $1 \mathrm{~h}$, Radiata pine bark: $1 \mathrm{~g}$ (o.d) within $5 \mathrm{~min}$, and the extraction equilibrium was reached within $20 \mathrm{~min}$. However, in the extraction of large quantities of bark polyphenols, an extraction time of $1 \mathrm{~h}$ would be recommended.

It should be noted here that the purpose of this study was to obtain suitable conditions to obtain $>60 \%$ of extracts, so the amount of $\mathrm{NaOH}$ required to achieve this target was investigated. Thus, with an extraction time of $1 \mathrm{~h}$ and a liquor ratio of 5 , the extraction yield and extract $\mathrm{pH}$ were determined. As presented in Table 4, when 17 and $18 \%$ of $\mathrm{NaOH}$ relative to the bark weight were used for the polyphenol extraction, yields of 61 and $62 \%$ were obtained, in addition to $\mathrm{pH}$ values of 11.9 and 12.1 , respectively. Therefore, to obtain the targeted yield of $>60 \%$ and $\mathrm{pH}$ value of 11 to 12 , the optimum extraction conditions were a liquor ratio 5,17 to $18 \% \mathrm{NaOH}$, an extraction temperature of $100{ }^{\circ} \mathrm{C}$, and an extraction time of $60 \mathrm{~min}$.

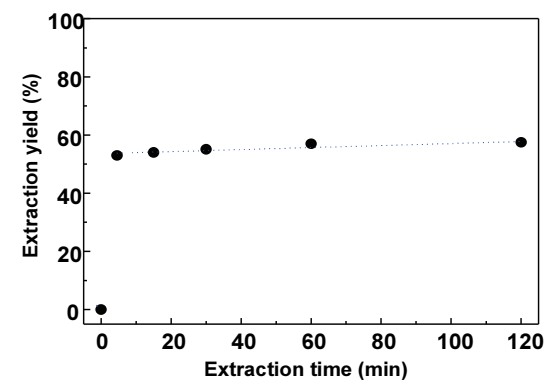

Fig. 2. Variation in the $\mathrm{NaOH}$ extract yield by changing the extraction time (bark: $1 \mathrm{~g}$ (o.d), liquor ratio: 5, $\mathrm{NaOH}: 0.125 \mathrm{~g})$.

Table 4. Extraction Yields and Extract $\mathrm{pH}$ Values with Varying Amounts of $\mathrm{NaOH}$

\begin{tabular}{ccccc}
\hline Liquor ratio & $\mathrm{NaOH}(\mathrm{g})$ & $\begin{array}{c}\text { Extraction } \\
\text { time (min) }\end{array}$ & $\begin{array}{c}\text { Extraction } \\
\text { yield (\%) }\end{array}$ & $\mathrm{pH}$ \\
\hline \hline \multirow{2}{*}{5} & 0.125 & & 56.99 & N.D \\
& 0.17 & 60 & 60.91 & 11.9 \\
& 0.18 & & 62.26 & 12.1 \\
\hline
\end{tabular}

N.D.: Not determined, Radiata pine bark: 1 g (o.d) 


\subsection{Characteristics of the alkaline extracts}

\subsubsection{IR spectra}

Fig. 3 shows the IR spectra of the reference hot water extract and the neutralized sample after $\mathrm{NaOH}$ extraction. In the case of the hot water extract, absorption bands indicating the presence of polyhydric flavonoids were found at 3368, 1612, and $1067 \mathrm{~cm}^{-1}$, while bands at 1530 and $780 \mathrm{~cm}^{-1}$ indicated the presence of hydroxyl groups in the B-ring of the flavanol moiety (Yazaki and Hillis 1977; Sotoet al. 2005).

However, the neutralized extract displayed considerably weaker absorption bands, with the exception of

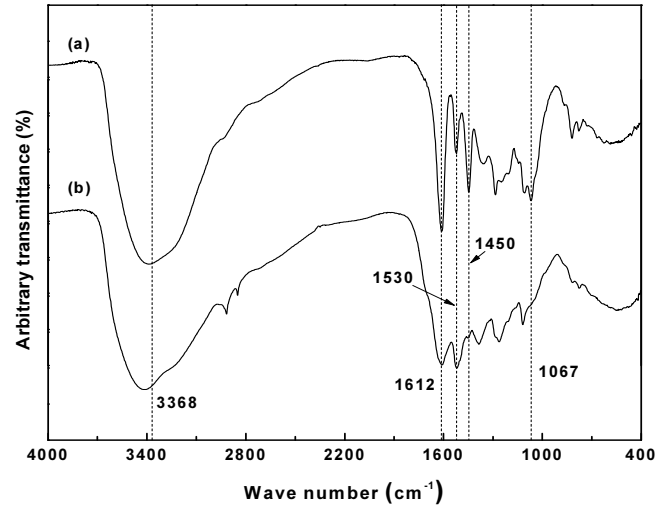

Fig. 3. IR spectra of (a) hot water extract and (b) neutralized sample after $\mathrm{NaOH}$ extraction. that at $3368 \mathrm{~cm}^{-1}$, which was caused by the severe denaturation of the bark polyphenols. These observations concur with the report by Basso et al. (2014), whereby phlobaphene generation, rearrangement, and condensation reactions occur during the extraction process of pine bark.

\subsection{2. ${ }^{13} \mathrm{C}$ NMR analysis}

For NMR analysis of the bark polyphenols, the majority of samples exhibited a good solubility in a mixture of deuterated acetone and $\mathrm{D}_{2} \mathrm{O}$. However, after dissolution of the neutralized extract in $\mathrm{D}_{2}$ Obut upon the addition of deuterated acetone, neutral salts in the sample were precipitated. To address this issue, the mixture was heated to improve the sample solubility. Upon cooling, some precipitation occurred, and the viscosity increased, thereby rendering transfer of the solution to the NMR tube challenging. Thus, the precipitate was instead removed by centrifugation, and the supernatant was subjected to ${ }^{13} \mathrm{C}$ NMR analysis. However, no peaks were obtained, so the neutralized extracts were desalted by passing through a cation exchange resin. The desalted samples were dissolved in acetone- $d_{6} / \mathrm{D}_{2} \mathrm{O}$ solvent systems, and some remaining precipitates were removed by centrifugation. The ${ }^{13} \mathrm{C}$ NMR spectra of the obtained samples are shown in Fig. 4, whereby the asterisk (*) in Fig. 4(b) represents

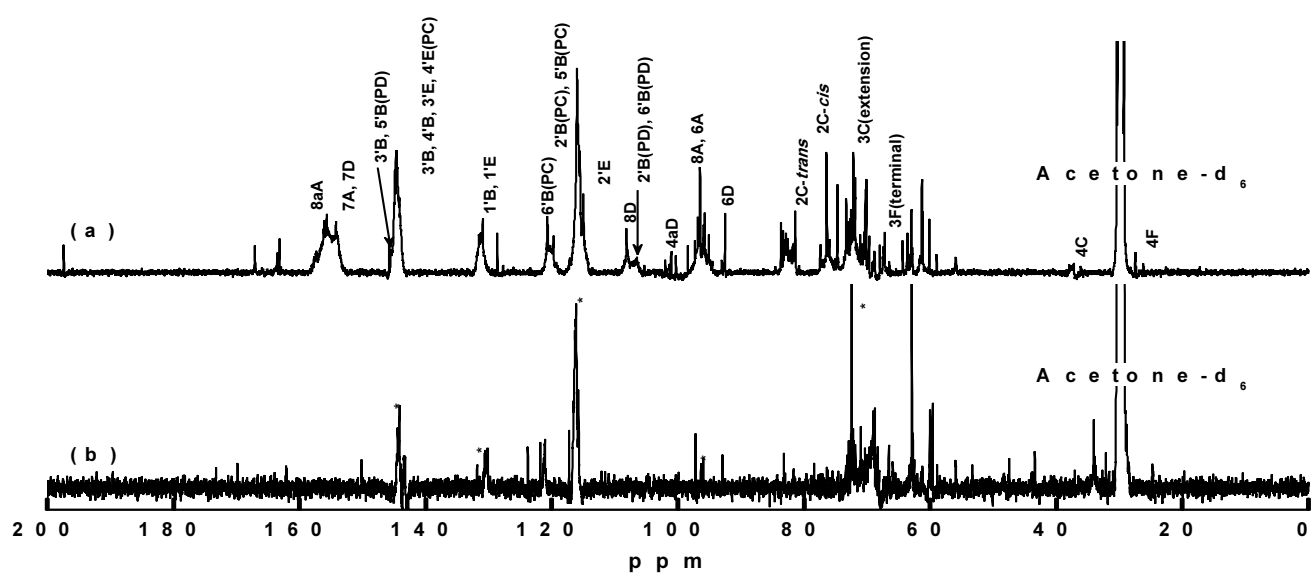

Fig. 4. ${ }^{13} \mathrm{C}$ NMR spectra of (a) the hot water extract, and (b) the neutralized and desalted sample after $\mathrm{NaOH}$ extraction. 


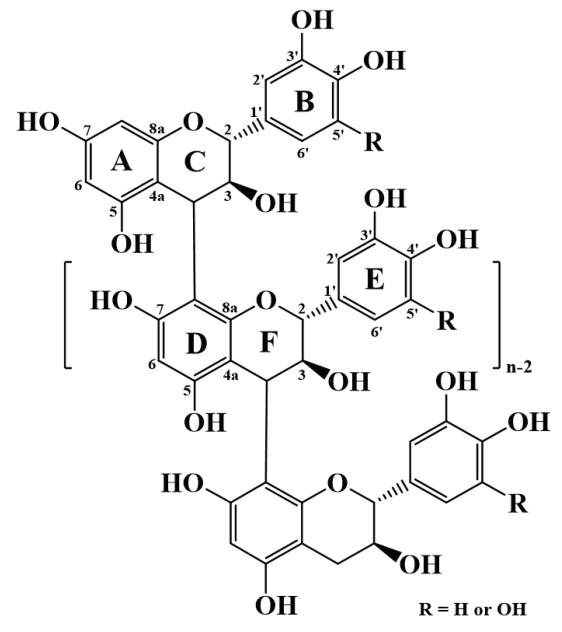

$\mathbf{R}=\mathbf{H}$ : Procyanidin, $\mathbf{R}=\mathbf{O H}$ : Prodelphinidin

Fig. 5. Chemical structure of proanthocyanidin from radiata pine bark.

the peak corresponding to the peak of the reference hot water extract. Fig. 5 shows the chemical structure of proanthocyanidin from radiata pine bark.

The ${ }^{13} \mathrm{C}$ NMR spectra of the two samples were analyzed based on the previous reports (Czochanska et al. 1980; Porter et al. 1982; Davis et al. 1996), and peaks corresponding to procyanidin (PC) and prodelphinidin (PD) were identified for the neutralized extract. The peaks observed at $116 \mathrm{ppm}\left(2^{\prime} \mathrm{B}, 5^{\prime} \mathrm{B}\right)$, $120 \mathrm{ppm}\left(6^{\prime} \mathrm{B}\right)$, and $145 \mathrm{ppm}\left(3^{\prime} \mathrm{B}, 4^{\prime} \mathrm{B}, 3^{\prime} \mathrm{E}, 4^{\prime} \mathrm{E}\right)$ indicated the existence of $\mathrm{PC}$ units in the PAs. All three peaks were observed in the reference hot water extract sample, but only those at 116 and $145 \mathrm{ppm}$ were observed in the neutralized extract. Peaks corresponding to the $6 \mathrm{~A}, 8 \mathrm{~A}, 1^{\prime} \mathrm{B}$, and $1^{\prime} \mathrm{E}$ carbon atoms were observed, and no other peaks associated with PAs were found. These results indicated that some low molecular weight products resulted from severe chemical modifications of the bark polyphenols during the alkali extraction process, which correlates with the above-described IR spectroscopy observations.

\section{CONCLUSIONS}

The use of alkaline extract from radiata pine (Pinus radiata) bark as raw materials for bio-foams is of current interest. Through this study the optimal conditions for the mass extraction of polyphenols from radiata pine bark was determined. The optimal extraction conditions were a liquor ratio of 5 , a 17 to $18 \%$ ratio of $\mathrm{NaOH}$ based on the bark weight, a temperature of 100 ${ }^{\circ} \mathrm{C}$, and an extraction time of $60 \mathrm{~min}$. Under these conditions, the yield of the alkaline extract obtained from the pine bark powder was $\sim 60 \%$, and its $\mathrm{pH}$ value was $\sim 12$. Structural analysis of the alkaline extract prepared using these optimized conditions indicated that significant chemical modification took place in the bark polyphenols during alkali extraction. The alkaline extract of radiata pine bark was barely soluble in the solvent employed for structural analysis due to the condensation reactions and structure rearrangements that took place during the alkali extraction process. For the production of bio-foams, chemical modification is required to increase the solubility of the alkaline extract in polyol. In the future study, chemical modification, such as hydroxypropylation, of extract or development of a new alkali extraction method should be conducted. Then, the alkaline extract could be used to prepare the bio-foam as substitution of polyol.

\section{ACKNOWLEDGMENT}

This study was supported by a Research Project Grant (FP0600-2017-01) provided by the National Institute of Forest Science (NIFoS), Korea.

\section{REFERENCES}

Basso, M.C., Giovando, S., Pizzi, A., Lagel, M.C., Celzard, A. 2014. Alkaline tannin rigid foams, Journal of Renewable Materials 2(3): 182-185. 
Czochanska, Z., Foo, L.Y., Newman, R.H., Porter, L.J. 1980. Polymeric proanthocyanidins. Stereochemistry, structural units, and molecular weight. Journal of the Chemical Society, Perkin Transactions 1: 2278-2286.

Davis, A.L., Cai, Y., Davies, A.P., Lewis, J.R. 1996. ${ }^{1} \mathrm{H}$ and ${ }^{13} \mathrm{C}$ NMR assignments of some green tea polyphenols. Magnetic Resonance in Chemistry 34: 887-890.

Kim, J.W., Um, M., Lee, J.W. 2018. Antioxidant activities of hot water extracts from different parts of Rugosa rose (Rosa rugosa Thunb.). Journal of the Korean Wood Science and Technology 46(1): $38-47$.

Korean Law No. 16711. 2019. Act on sustainable use of wood, Seoul, South Korea.

Korea Forest Service (KFS). 2020. Statistical Yearbook of Forestry (No. 11-1400000-000001-10), Deajeon, South Korea.

Ku, C.S., Jang, J.P., Mun, S.P. 2007. Exploitation of polyphenol-rich pine barks for potent antioxidant activity. Journal of Wood Science 53: 524-528.

Masendra, M., Ashitani, T., Takahashi, K., Susanto, M., Lukmandaru, G. 2019. Hydrophilic extracts of the bark from six Pinus species. Journal of the Korean Wood Science and Technology 47(1): 80-89.

Mun, S.P. 2008. Extraction and separation of proanthocyanidins from pine bark, Korea Patent No. 10-0817876.

Mun, S.P., Ku, C.S., Kim, J.P. 2010. Adsorption of metal and uranyl ions onto amidoximated Pinus densiflora bark. Wood Science and Technology 44: 283-299.

Nam, J.B., Oh, G.H., Yang, S.M., Lee, S.E., Kang, S.G. 2018. Evaluation of antioxidant activities of water extract from microwave torrefied oak wood. Journal of the Korean Wood Science and Technology 46(2): 178-188.

Song, K.H., Mun, S.P., Kim, D.S., Hong, Y.K. 2009.
Dyeability with silk fabrics and chemical composition of natural dye Pinux ${ }^{\mathrm{TM}}$ manufactured from Pinus radiata bark. Korean Journal of Human Ecology 18(6): 1315-1321.

Park, E.Y., Choi, J.M. 2014. Development of root media containing pine bark for cultivation of horticultural crops. Korean Journal of Horticultural Science \& Technology 32(4): 499-506.

Porter, L.J., Newman, R.H., Foo, L.Y., Wong, H., Hemingway, R.W. 1982. Polymeric proanthocyanidins. ${ }^{13}$ C N.M.R. studies of procyanidins. Journal of the Chemical Society, Perkin Transactions 1: 1217-1221.

Soto, R., Freer, J., Baeza, J. 2005. Evidence of chemical reactions between di- and poly-glycidyl ether resins and tannins isolated from Pinus radiata D. Don bark, Bioresource Technology 96(1): 95-101.

Tondi, G., Pizzi, A., Olives, R. 2008. Natural tanninbased rigid foams as insulation for doors and wall panels. Maderas Ciencia y tecnología 10(3): 219227.

TAPPI T-204. 2007. Solvent extractives of wood and pulp, TAPPI Press, Atlanta, GA.

TAPPI T-207 cm-99. 2008. Water solubility of wood and pulp, TAPPI Press, Atlanta, GA.

TAPPI T-211. 2002. Ash in wood, pulp, paper, and paperboard, TAPPI Press, Atlanta, GA.

TAPPI T-212 om-02. 2002. One percent sodium hydroxide solubility of wood and pulp, TAPPI Press, Atlanta, GA.

TAPPI T-222 om-11. 2011. Acid-insoluble lignin in wood and pulp, TAPPI Press, Atlanta, GA.

Yazaki, Y., Hillis, W. 1977. Polyphenolic extractives of Pinus radiata bark. Holzforschung 31(1): 20-25.

Zhou, X.A., Pizzi, A., Sauget, H., Nicollin, A., Rode, X. Li., Celzard, A., Pasch, K. 2013. Lightweight tannin foam/composites sandwich panels and the coldset tannin adhesive to assemble them. Industrial Crops and Products 43: 255-260. 